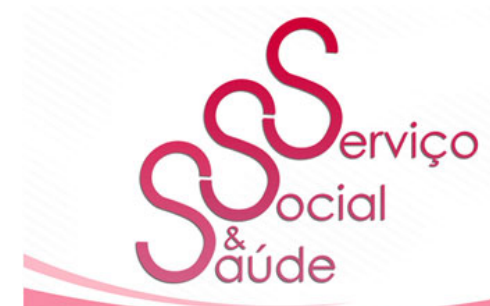

ISSN 2446-5992

(c) (1)(2)

doi: 10.20396/sss.v17i1.8655202

\title{
NECESSIDADES E RECURSOS SOCIAIS EM DOENTES RENAIS CRÓNICOS HEMODIALISADOS
}

\author{
NEEDS AND SOCIAL RESOURCES OF HEMODIALYSIS PATIENTS \\ WITH CHRONIC KIDNEY DISEASE
}

\author{
Marta Freitas Olim ${ }^{I}$ \\ Sónia Guadalupe ${ }^{2}$ \\ Sara Zeferino ${ }^{3}$ \\ Mara Marques ${ }^{4}$ \\ Patrícia Neves ${ }^{5}$ \\ Joana Conceição ${ }^{6}$
}

\begin{abstract}
RESUMO
O estudo apresenta dados acerca da provisão social das necessidades de doentes insuficientes renais crónicos em tratamento de hemodiálise em Portugal. Estudo descritivo dos dados dos processos sociais de 1436 doentes no ano de 2017. Na maioria são do sexo masculino $(60,7 \%)$ e têm idades entre os 19 e os 97 anos $(M=66,3 ; D P=15,8)$. Foram sinalizadas 2550 necessidades, 1,78 sinalizações em média por doente. Do total, $48 \%$ apresentam necessidades de apoio material/instrumental, $31,2 \%$ evidenciaram necessidades de advocacy e de intervenção psicossocial, sendo estas e as de apoio logístico que apresentam um número mais elevado de sinalizações $(M=1,257 ; M=1,431$, respetivamente). Em $63,4 \%$ dos casos a resposta foi adequada. As necessidades não satisfeitas são por resposta desadequada ou por inexistência de resposta $(6,2 \% ; 5,5 \%)$, ou ainda por não adesão do doente/família $(14,1 \% ; 6,1 \%)$. Analisadas as
\end{abstract}

\footnotetext{
${ }^{1}$ Mestre Serviço Social, Diaverum Portugal. https://orcid.org/0000-0001-5151-9425. E-mail Marta.Olim@diaverum.com. Telefone +351 219252400.

2 Doutorada em Serviço Social, Instituto Superior Miguel Torga (ISMT), Centro de Estudos e Investigação em Saúde da Universidade de Coimbra (CEISUC). E-mail: guadalupe@ismt.pt https://orcid.org/0000-0003-4898-3942

${ }^{3}$ Diaverum Portugal. E-mail: Sara.Zeferino@diaverum.com.

${ }^{4}$ Diaverum Portugal. E-mail: Mara.marques@diaverum.com.

${ }^{5}$ Diaverum Portugal. E-mail: Patrícia.neves@diaverum.com.

${ }^{6}$ Diaverum Portugal. E-mail: Joana.conceicao@diaverum.com

\begin{tabular}{|l|l|l|l|l|l|l|} 
Serv. Soc. \& Saúde & Campinas, SP & v. 17 & n. 1 [25] & p.31-64 & jan.jun. 2018 & e-ISSN 2446-5992
\end{tabular}
}



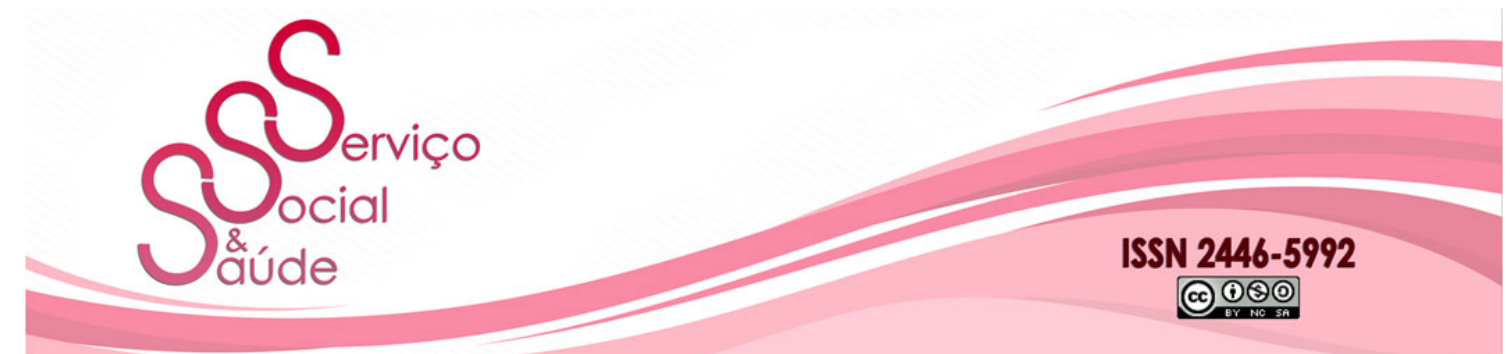

doi: 10.20396/sss.v0i0.00000000

diferenças sociodemográficas, as pessoas viúvas registam um número de necessidades superior aos outros estados civis $(p<0,01)$, e os doentes em famílias de acolhimento ou instituições $(p<$ 0,01). O conhecimento das necessidades destes doentes é fulcral para o Serviço Social favorecer programas de provisão às necessidades dominantes e para grupos de especial atenção.

PALAVRAS-CHAVE: Doença renal crónica. Hemodiálise. Serviço Social. Necessidades.

Recursos. Apoio social.

\section{ABSTRACT}

This study presents data on the social provision of needs of hemodialysis patients with chronic kidney disease in Portugal. A descriptive study of patients' social processes data of 1436 CKD patients in 2017. Most are male (60.7\%) and are between 19 and 97 years old $(M=66.3 ; S D=$ 15.8). Social workers signaled 2550 needs, 1.78 needs on average per patient. From the total, $48 \%$ presented material / instrumental support needs, $31.2 \%$ evidenced needs for advocacy and psychosocial intervention, being these and the logistical support needs, that present a higher average number of needs $(M=1,257 ; M=1.431$, respectively). In $63.4 \%$ of the cases the response was adequate. Unmet need is due to inadequate response or lack of response $(6.2 \%$, $5.5 \%)$, or due to non-compliance of the patient or family $(14.1 \%, 6.1 \%)$. When the sociodemographic differences were analyzed, widows had a higher number of needs than other civil status ( $p<0.01)$, as well as patients in host families or institutions when compared to other family typologies $(p<0.01)$. Knowing the needs of CKD patients is central to Social Work to present proposals of programs for needs' provision and focused on special attention groups.

Knowing the needs of CKD patients is central to Social Work to present proposals of programs for needs' provision and focused on special attention groups.

KEYWORDS: Chronic renal disease. CKD. Hemodialysis. Social work. Needs. Resources. Social Support

\section{INTRODUÇÃO}

A doença renal crónica (DRC) e o tratamento dialítico representam um desafio diário na vida quotidiana do doente, com impactes a múltiplos níveis. Na literatura são apontados diversos fatores de vulnerabilidade clínica, social e psicológica (JANSEN; RIJKEN; HEIJMANS; KAPTEIN; GROENEWEGEN, 2012; SALATI; HOSSNE; PESSINI, 2011) que o dialisado crónico enfrenta e impõem necessidades específicas de resposta. A DRC e os seus tratamentos implicam diferentes alterações e limitações com

\begin{tabular}{|l|l|l|l|l|l|l|} 
Serv. Soc. \& Saúde & Campinas, SP & v. 17 & n. 1 [25] & p.31-64 & jan./jun. 2018 & e-ISSN $2446-5992$
\end{tabular}




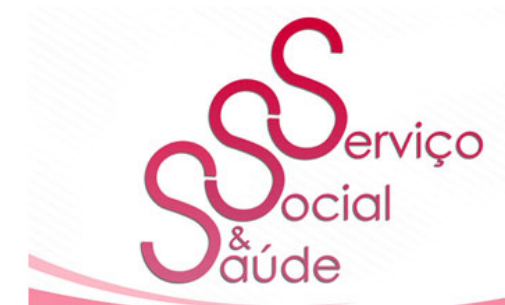

\section{ISSN 2446-5992}

(c) (1)(8)

doi: 10.20396/sss.v0i0.00000000

impacte psicossocial (MANSUR; DAMASCENO; BASTOS, 2012), tais como restrições alimentares (IBRAHIM, 2008), limitações à autonomia (FERREIRA, 2010) e condicionamento na organização da vida quotidiana, na capacidade para o trabalho e na participação social (JANSEN et al., 2012; TIRAPANI, 2012).

A doença apresenta sempre custos diretos para o doente a sua família (alguns custos com medicação, exames complementares de diagnóstico, alimentação específica, transportes para tratamentos) e custos indiretos (baixa a assiduidade no trabalho, perda de produtividade e dificuldade de conciliação entre o trabalho e o cuidar), baixando o rendimento do doente sem compensação total pelos sistemas de proteção social (GUADALUPE, 2012). O condicionamento físico está muito associado à perda de mobilidade, fadiga e prostração que, por vezes, impedem a participação em eventos sociais e limitam as atividades de vida diária. Este quadro continuado, juntamente com as exigências associadas ao tratamento, influencia de forma negativa a capacidade para manter a atividade laboral. A perda de produtividade associada à DRC (para doentes e seus cuidadores) tem sido abordada através da perspetiva do capital humano, estimandose custos sociais indiretos elevados associados a tais perdas (TURCHETTI et al., 2017), sendo que a doença abre frequentemente caminho à deterioração das condições de vida e ao empobrecimento (GUADALUPE, 2012).

Pelo facto de se tratar de uma doença crónica, estes doentes estão ainda sujeitos à imprevisibilidade das intercorrências e à incerteza quanto a um prognóstico, gerando instabilidade emocional e social nos mesmos, com expressão de necessidades progressivas ou flutuantes no tempo. Todas estas circunstâncias têm também implicações na dinâmica familiar. A doença não coloca apenas em causa a vida familiar quotidiana mais imediata, mas compromete frequentemente planos futuros do próprio doente e da família, de cada um dos seus membros e no seu todo (GUADALUPE, 2012). Apesar de a doença ser uma experiência universal, que todos já experimentámos 


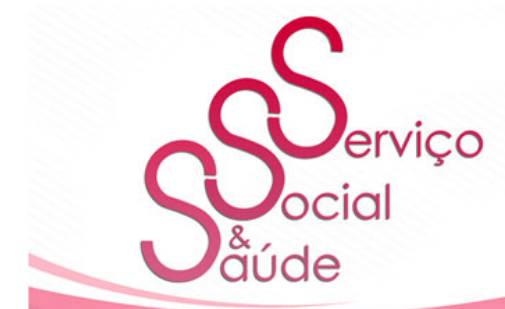

\section{ISSN 2446-5992}

(c) (1)(8)

doi: $10.20396 /$ sss.v0i0.00000000

ou iremos experimentar, esta constitui sempre um enorme desafio na vida, sendo tanto maior quanto mais inesperadamente surgir, maior gravidade apresentar na sua evolução e quanto maior grau de incapacidade trouxer (ROLLAND, 2000). O impacte da doença na família faz-se sentir a nível estrutural, processual e emocional (GÓNGORA, 1996; SOUSA; RELVAS; MENDES, 2007) e vai depender de múltiplas variáveis associadas à doença e à família, no cruzamento entre os ciclos vitais da família, do indivíduo e das características e fases da própria (ROLLAND, 1995; GUADALUPE, 2012).

$\mathrm{O}$ ajustamento e adaptação à doença e às suas exigências dependem muito de como se lida com as necessidades suscitadas pela doença e como são enfrentadas as adversidades (WALSH, 2005). A satisfação de necessidades e de autonomia são fundamentais para garantir a participação social dos indivíduos (WHO, 2007; DOYAL; GOUGH, 1991).

As redes de relações interpessoais, sobretudo a família e os amigos, são descritas como fontes fundamentais de suporte social com impacte direto e significativo no processo de adaptação à doença e tratamento (ROLLAND, 1995; WALSH, 2005; RASCANU; RADU, 2014). Este suporte social é consubstanciado em recursos de diversa natureza que suportam o individuo em situações de vulnerabilidade e pode constitui-se como suporte emocional, suporte instrumental ou material e suporte informativo (GUADALUPE, 2016). O suporte social é associado a uma melhor adesão ao tratamento, a uma maior sobrevida e a uma menor mortalidade em doentes renais crónicos em tratamento de hemodiálise, aumentando o risco de mortalidade nos doentes com diminuídas capacidades para estabelecer relações interpessoais com família e amigos, risco que persiste mesmo depois de controlados outros fatores que influenciam a mortalidade como a idade, raça, doença cardiovascular, causa da doença renal e o estado funcional (MCCLELLAN; STANWYCK; ANSON, 1993). O suporte e a coesão familiar são apontados como fatores que influenciam significativamente a sobrevivência 


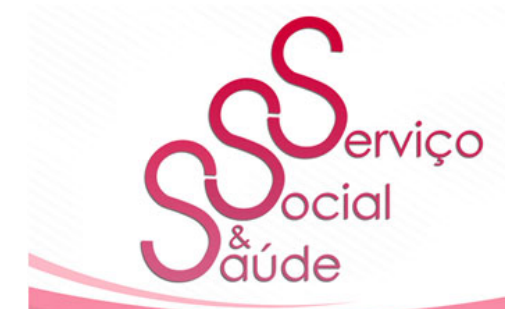

\section{ISSN 2446-5992}

(c) (1)(8)

doi: $10.20396 /$ sss.v0i0.00000000

nestes doentes, sendo que os pacientes com maior suporte social familiar apresentam melhores indicadores clínicos (PATEL; PETERSON; KIMMEL, 2005).

Tal como BRAGE (1998) entendemos que todas as necessidades humanas são necessidades sociais, sendo que a sociedade organiza formas distintas para a sua provisão e satisfação. Se tivermos por referência as necessidades enquanto "um conjunto multidimensional de perceções de carência e/ou um conjunto de danos físicos, psíquicos ou sociais cuja deficiente e/ou insatisfatória resposta e provisão obsta à plena inserção social dos indivíduos, eventualmente prejudicando a optimização das oportunidades de desenvolvimento da vida pessoal e colectiva" (PINTO; GUERRA; MARTINS; ALMEIDA, 2010: 19), centrar-nos-emos simultaneamente na sua manifestação e na sua provisão e nos recursos mobilizados para garantir a sua resposta e satisfação.

A necessidade de suporte social destes doentes tem sido sublinhada, particularmente no sentido de reforçar o ajustamento, o coping e a autonomia (TAYLOR; COMBES, 2014). O suporte dado pela equipa interdisciplinar tende a favorecer a adesão ao tratamento e a qualidade de vida. Uma intervenção centrada nas diversas necessidades do doente, com diferentes enfoques (nomeadamente, social, psicológico, nutricional e educacional), tendo como principal preocupação o envolvimento dos mesmos nos processos de doença e tratamento, permite um melhor ajustamento à doença e tratamento, diminuição da progressão da doença e diminuição das hospitalizações (JOHNS et al., 2015). As interações entre fatores de risco psicossociais, potencialmente modificáveis, favorecem o aumento ou diminuição na mortalidade e na morbilidade na DRC (CUKOR, COHEN; PETERSON; KIMMEL, 2007). Fatores como a diminuição da satisfação conjugal, uma dinâmica familiar perturbada e o nível socioeconómico baixo têm sido associados a resultados de saúde mais desfavoráveis (CUKOR et al., 2007). 


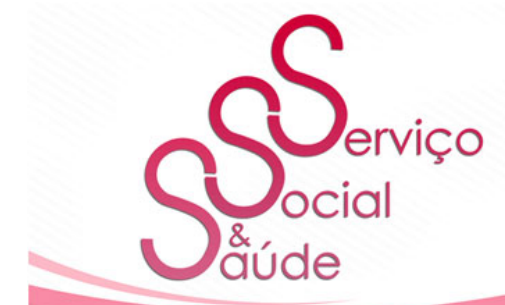

\section{ISSN 2446-5992}

(c) (1)(2)

doi: $10.20396 /$ sss.v0i0.00000000

O Serviço Social, como parte integrante da equipa interdisciplinar, tem um papel determinante no apoio a estes doentes e famílias, intervindo multidimensionalmente no sentido da provisão das necessidades identificadas (BEDER, 1999). O impacte da intervenção do Serviço Social nem sempre é imediato, apontando-se para melhorias no bem-estar geral, para um melhor ajustamento à doença e para a diminuição da sintomatologia depressiva, por exemplo, em doentes apoiados pelo Serviço Social (MCCOOL et al., 2011). Operacionalmente, a avaliação e a resposta às necessidades são processos dinâmicos, entendendo-se que o Serviço Social tem um papel central neste domínio, apesar das controvérsias conceptuais e ideológicas em torno da ideia de necessidade (DOVER, 2016). No contexto do trabalho do assistente social na área da saúde, a focalização na provisão de necessidades pode ser atravessada por objetivos compensatórios na sua satisfação, passando pelo favorecimento do bem-estar, da qualidade de vida, da autonomia, pela garantia de um direito humano e de cidadania, pela garantia de acesso a um recurso, assim como pela capacitação, pela participação social, pela emancipação ou mesmo pelo alcance de uma maior justiça social.

Reconhecendo a importância da intervenção do Serviço Social em doentes renais crónicos em hemodiálise, o presente estudo tem como objetivo caracterizar o tipo de necessidades sociais sentidas por estes doentes, assim como a sua provisão por parte do Serviço Social, no entrecruzamento de problemas, suportes e recursos (SHEPPARD; WOODCOCK, 1999), contribuindo para a análise e sistematização do conhecimento acerca das suas necessidades com vista a melhorar a intervenção numa perspectiva holística. 


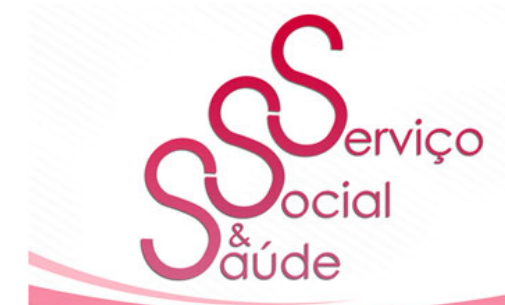

ISSN 2446-5992

(c) (i) (2)

doi: 10.20396/sss.v0i0.00000000

\section{MATERIAL E MÉTODOS}

\section{Método}

O estudo recorre a dados recolhidos ao longo do ano de 2017 por uma equipa de assistentes sociais de uma empresa privada na área da saúde em 25 clínicas de hemodiálise em Portugal. Os dados foram sistematizados a partir dos processos sociais, tendo sido obtidos através de entrevistas semiestruturadas de diagnóstico social e de seguimento, respeitando os princípios éticos e deontológicos da profissão ${ }^{7}$. As categorias operacionais usadas na tipificação das necessidades emergiram da análise de conteúdo prévia dos registos nos processos sociais.

Recorremos à estatística descritiva e inferencial na análise dos dados. Foi testada a normalidade da distribuição das variáveis em análise através do Teste KolmogorovSmirnov, e, verificada a sua violação, optámos pelos testes não paramétricos. Recorremos ao teste do Qui-quadrado para analisar associações entre variáveis, tendo calculado a medida de associação de Phi para caracterizar a intensidade e a direção da associação entre as variáveis. Usámos os testes de Mann-Whitney e de Kruskal Wallis para avaliar diferenças nas médias de sinalizações de necessidades segundo variáveis sociodemográficas.

\section{Participantes}

Participam no estudo 1436 doentes insuficientes renais crónicos hemodialisados, acompanhados em clínicas em Portugal. Estes têm entre os 19 e os 97 anos de idade, com uma média de 66,3 anos $(D P=15,8)$, situando-se sobretudo nas faixas etárias acima dos 65 anos de idade (59\%), sendo a maioria do sexo masculino $(60,7 \%)$ e

\footnotetext{
${ }^{7}$ A recolha de dados obteve parecer positivo da Comissão de Ética da Diaverum, instituição onde foram recolhidos os dados, tendo os dados sido sistematizados mantendo o anonimato e confidencialidade.
}

\begin{tabular}{|l|l|l|l|l|l|l} 
Serv. Soc. \& Saúde & Campinas, SP & v. 17 & n. 1 [25] & p.31-64 & jan./jun. 2018 & e-ISSN $2446-5992$ \\
\hline
\end{tabular} 


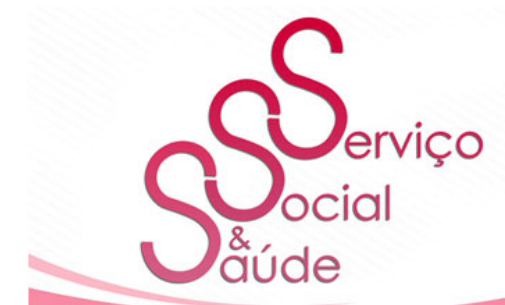

ISSN 2446-5992

(c) (1) (3)(2)

doi: 10.20396/sss.v0i0.00000000

casados (57,5\%). A maior parte apresenta o $4 .^{\circ}$ ano do ensino básico como habilitações literárias $(49,3 \%)$. A maioria dos participantes é autóctone $(85,2 \%)$, sendo os restantes oriundos de países dos PALOP (12,4\%), de países Europeus $(0,6 \%)$ e de países de outras zonas do mundo $(1,7 \%)$ (Tabela 1$)$.

Tabela1.

Características sociodemográficas

\begin{tabular}{|c|c|c|}
\hline$N=1436(100 \%)$ & $n$ & $\%$ \\
\hline \multicolumn{3}{|l|}{ Sexo } \\
\hline Masculino & 871 & 60,7 \\
\hline Feminino & 565 & 39,4 \\
\hline \multicolumn{3}{|l|}{ Idade (Grupo etário) } \\
\hline Transição para vida adulta e Jovem adultícia (19-35 anos) & 63 & 4,4 \\
\hline Adultícia (36-64 anos) & 526 & 36,6 \\
\hline Idoso-Jovem (65-74 anos) & 341 & 23,8 \\
\hline Idoso (75-84 anos) & 355 & 24,7 \\
\hline \multirow[t]{2}{*}{ Idoso-idoso $(>=85$ anos $)$} & 151 & 10,5 \\
\hline & $M(D P)$ & Min-Máx \\
\hline \multirow[t]{2}{*}{ Idade } & $66,3(15,8)$ & $19-97$ \\
\hline & $n$ & $\%$ \\
\hline \multicolumn{3}{|l|}{ Estado Civil } \\
\hline Solteiro(a) & 224 & 15,6 \\
\hline Casado(a) / Unido(a) de Facto & 825 & 57,5 \\
\hline Divorciado(a)/ Separado(a) & 131 & 9,1 \\
\hline Viúvo(a) & 256 & 17,8 \\
\hline \multicolumn{3}{|l|}{ Habilitações Literárias } \\
\hline Sem escolaridade & 169 & 11,8 \\
\hline Ensino Básico $1^{\circ}$ Ciclo (1-4 ano) & 708 & 49,3 \\
\hline Ensino Básico $2^{\circ}$ Ciclo (5-6 ano) & 162 & 11,3 \\
\hline Ensino Básico $3^{\circ}$ Ciclo (7-9 ano) & 154 & 10,7 \\
\hline Secundário/ Curso profissional (10-12 ano) & 135 & 9,4 \\
\hline Bacharelato/ Licenciatura & 102 & 7,1 \\
\hline Mestrado/ Doutoramento & 6 & 0,4 \\
\hline \multicolumn{3}{|l|}{ Origem } \\
\hline Portugal & 1224 & 85,2 \\
\hline $\begin{array}{l}\text { PALOP (Angola, Cabo Verde, Guiné Bissau, Moçambique, São } \\
\text { Tomé e Príncipe) }\end{array}$ & 178 & 12,4 \\
\hline $\begin{array}{l}\text { Países Europeus (Alemanha, Bulgária, França, Malta, Ucrânia, } \\
\text { Roménia, Suíça) }\end{array}$ & 9 & 0,6 \\
\hline $\begin{array}{l}\text { Outras Origens (Brasil, China, Ilhas Virgens Britânicas, India, } \\
\text { Macau, Nigéria, Paquistão, Porto Rico, Quénia, Venezuela }\end{array}$ & 25 & 1,7 \\
\hline
\end{tabular}

Notas: PALOP - Países Africanos de Língua Oficial Portuguesa 


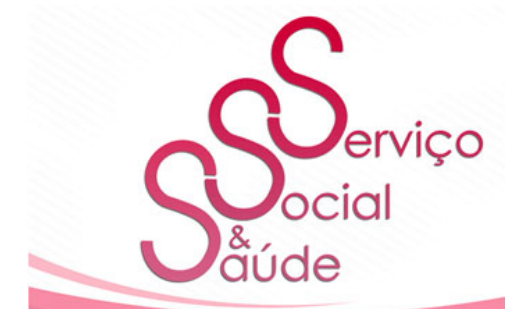

ISSN 2446-5992

(c) (1)(2)

doi: $10.20396 /$ sss.v0i0.00000000

A maior parte dos participantes integra famílias nucleares com filhos $(47,1 \%)$, seguidos dos que integram famílias alargadas (13,2\%), famílias unipessoais, isto é, vivem sós $(12,9 \%)$ e famílias monoparentais $(10,3 \%)$. Os restantes arranjos familiares apresentam-se percentualmente menos representadas, mas salientamos a existência de $5,2 \%$ de sujeitos integrados em instituições e 3,9\% de membros de agregados com coabitantes não aparentados (Tabela 2).

\section{Tabela 2.}

Situação Sociofamiliar

\begin{tabular}{lcc}
\hline$N=1436(100 \%)$ & $\boldsymbol{n}$ & $\boldsymbol{\%}$ \\
\hline Família Nuclear com Filhos & 677 & 47,1 \\
Família Nuclear sem Filhos & 64 & 4,5 \\
Família Alargada & 189 & 13,2 \\
Família Monoparental & 148 & 10,3 \\
Família Reconstituída & 40 & 2,8 \\
Família Unipessoal & 181 & 12,6 \\
Agregados com coabitantes não aparentados & 56 & 3,9 \\
Família de Acolhimento & 6 & 0,4 \\
Integrado em Instituição & 75 & 5,2 \\
TOTAL & 1436 & 100,0 \\
\hline
\end{tabular}

\section{RESULTADOS}

Foram sinalizadas 2550 necessidades junto dos 1436 participantes ao longo de 1 ano pelo Serviço Social. A maioria dos participantes foi sinalizada por uma necessidade $(58,6 \%)$, seguindo-se os que apresentaram duas necessidades $(23,5 \%)$, três ou quatro necessidades $(13,8 \%)$ e cinco ou mais necessidades $(4,1 \%)$, tendo-se registado três casos únicos de indivíduos com 10, 13 e 15 necessidades, podendo representar diversas solicitações de uma mesma necessidade (Tabela 3). 


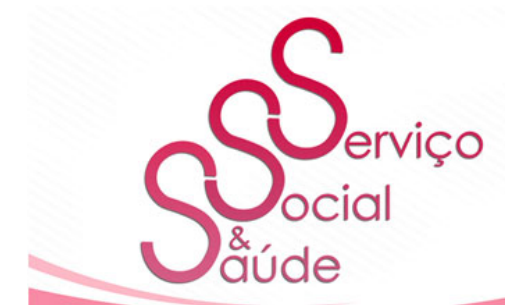

ISSN 2446-5992

(1) (1)(-)

doi: 10.20396/sss.v0i0.00000000

Tabela 3.

Frequência de necessidades sinalizadas

\begin{tabular}{rrccc}
\hline Frequência agrupada: & & $\boldsymbol{n}$ & $\%$ & $\begin{array}{c}\text { Medidas } \\
\text { descritivas }\end{array}$ \\
\hline 1 & 842 & 58,6 & $M=1,78$ \\
2 & 338 & 23,5 & $D P=1,30$ \\
$3-4$ & 198 & 13,8 & Mín $=1$ \\
$>=5$ & 58 & 4,1 & Máx $=15$ \\
\hline TOTAL & 1436 & 100,0 &
\end{tabular}

A sinalização de necessidades foi efetuada ao nível de cinco categorias operacionais de necessidades. Do total de sujeitos $(N=1436), 48 \%$ apresentaram necessidades de apoio material ou instrumental, 32,2\% evidenciaram necessidades de advocacy e de intervenção psicossocial, 27,2\% solicitaram apoio logístico, 17,8\% apresentaram necessidade de integração em resposta social e 10,5\% em resposta ocupacional (Tabela 4).

Tabela 4.

Necessidades Sinalizadas: frequências por categoria

\begin{tabular}{lcccccc}
\hline & \multicolumn{2}{c}{$\begin{array}{c}\text { Apresenta } \\
\text { necessidades } \\
\text { sociais }\end{array}$} & $\begin{array}{c}\text { Não apresenta } \\
\text { necessidades } \\
\text { sociais }\end{array}$ & \multicolumn{2}{c}{ Total } \\
\hline Necessidades: & $\boldsymbol{n}$ & $\mathbf{\%}$ & $\boldsymbol{n}$ & $\mathbf{\%}$ & $\boldsymbol{n}$ & $\mathbf{\%}$ \\
\cline { 2 - 7 } Apoio Material e/ou Instrumental & $\mathbf{6 8 9}$ & $\mathbf{4 8 , 0}$ & 747 & 52,0 & 1436 & 100 \\
Apoio Logístico & $\mathbf{3 9 0}$ & $\mathbf{2 7 , 2}$ & 1046 & 72,8 & 1436 & 100 \\
Integração de Resposta Ocupacional & $\mathbf{1 5 1}$ & $\mathbf{1 0 , 5}$ & 1285 & 89,5 & 1436 & 100 \\
Integração de Resposta Social & $\mathbf{2 5 5}$ & $\mathbf{1 7 , 8}$ & 1181 & 82,2 & 1436 & 100 \\
Advocacy e Intervenção Psicossocial & $\mathbf{4 6 2}$ & $\mathbf{3 2 , 2}$ & 974 & 67,8 & 1436 & 100 \\
\hline
\end{tabular}

Notas: Advocacy (por vezes traduzido como Advocacia Social) refere-se à metodologia de Case Advocacy que promove a cidadania através da informação, defesa ou representação do utente e dos seus interesses junto de instituições, promovendo o acesso a recursos e a direitos. 


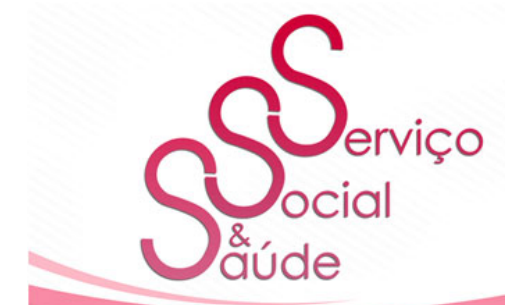

ISSN 2446-5992

(c) (1)(8)

doi: $10.20396 /$ sss.v0i0.00000000

41

Cada participante apresenta, fundamentalmente, uma necessidade numa só ocasião, como podemos verificar com as percentagens do valor modal (1) sempre superiores a $74 \%$ em cada categoria. No entanto, há participantes que apresentam necessidades múltiplas, que podem ser necessidades em categorias diversas ou várias necessidades ou solicitações na mesma categoria. Assim, as categorias que registam valores mais elevados nas sinalizações e/ou solicitações são as necessidades de apoio logístico $(M=$ 1,431, variando entre 1 e 15 sinalizações) e as necessidades de advocacy e de intervenção psicossocial ( $M=1,257$, variando entre 1 e 10 sinalizações). As restantes categorias apresentam valores médios e de amplitude mais baixos, evidenciando menos casos de necessidades múltiplas, variando entre 1 e 6 necessidades de apoio material e/ou instrumental e de necessidades de integração em resposta social, e entre 1 e 4 necessidades de integração em resposta ocupacional (Tabela 5).

Tabela 5.

Necessidades Sinalizadas (medidas descritivas)

\begin{tabular}{lccccccc}
\hline N=1436 (100\%) & $\boldsymbol{n}$ & $\boldsymbol{M}$ & $\boldsymbol{D P}$ & Min & Max & Mo & $\begin{array}{c}\text { \% Mo } \\
=1\end{array}$ \\
\hline Necessidades: & & & & & & & \\
$\quad$ Apoio Material e/ou Instrumental & 689 & 1,257 & 0,644 & 1,00 & 6,00 & 1,00 & 81,9 \\
$\quad$ Apoio Logístico & 390 & 1,431 & 1,096 & 1,00 & 15,00 & 1,00 & 74,4 \\
$\quad$ Integração de Resposta Ocupacional & 151 & 1,166 & 0,454 & 1,00 & 4,00 & 1,00 & 86.1 \\
$\quad$ Integração de Resposta Social & 255 & 1,267 & 0,646 & 1,00 & 6,00 & 1,00 & 80.8 \\
Advocacy e Intervenção Psicossocial & 462 & 1,357 & 0,823 & 1,00 & 10,00 & 1,00 & 76,8 \\
\hline
\end{tabular}

Encaradas globalmente as necessidades e respetivas respostas no processo interventivo, em $63,4 \%$ dos casos do total de participantes a resposta à(s) necessidade(s) sinalizada(s) foi adequada. Para $31,8 \%$ o processo de apoio mantém-se em aberto, a aguardar resposta. Já para 5,5\% não foi encontrada uma resposta para a necessidade sinalizada e para $6,2 \%$ as respostas revelaram-se desadequadas para a respetiva necessidade. 


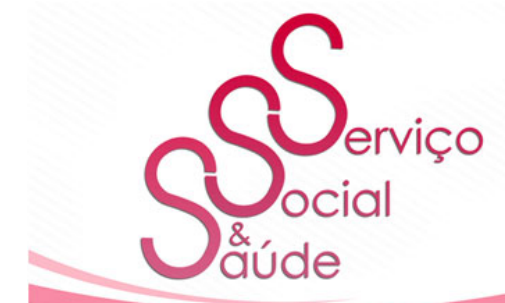

ISSN 2446-5992

(c) (i) (2)

doi: $10.20396 /$ sss.v0i0.00000000

42

Já em $14,1 \%$ e $6,1 \%$ não houve adesão do doente ou da família, respetivamente, ao plano de intervenção ou resposta fornecida. No decurso do processo interventivo junto dos participantes, registámos 14 casos em que houve alta por motivos clínicos, tendo-se verificado também 34 falecimentos (Tabela 6).

Tabela 6.

Situação no processo interventivo: frequências por categoria

\begin{tabular}{lcccccc}
\hline \multirow{2}{*}{$N=1436(100 \%)$} & \multicolumn{2}{c}{$\begin{array}{c}\text { Situação em que } \\
\text { houve resposta }\end{array}$} & $\begin{array}{c}\text { N.a. } \\
\text { Situação não } \\
\text { registada }\end{array}$ & \multicolumn{2}{c}{ Total } \\
\hline Situação: & $\boldsymbol{n}$ & $\mathbf{\%}$ & $\boldsymbol{n}$ & $\mathbf{\%}$ & $\boldsymbol{n}$ & $\boldsymbol{\%}$ \\
Resposta adequada & $\mathbf{9 1 0}$ & $\mathbf{6 3 , 4}$ & 526 & 36,6 & 1436 & 100 \\
A aguardar resposta & $\mathbf{4 5 7}$ & $\mathbf{3 1 , 8}$ & 979 & 68,2 & 1436 & 100 \\
Inexistência de resposta & $\mathbf{7 9}$ & $\mathbf{5 , 5}$ & 1357 & 94,5 & 1436 & 100 \\
Resposta desadequada & $\mathbf{8 9}$ & $\mathbf{6 , 2}$ & 1347 & 93,8 & 1436 & 100 \\
Não adesão da família & $\mathbf{8 8}$ & $\mathbf{6 , 1}$ & 1348 & 93,9 & 1436 & 100 \\
Não adesão do doente & $\mathbf{2 0 3}$ & $\mathbf{1 4 , 1}$ & 1233 & 85,9 & 1436 & 100 \\
Alta & $\mathbf{1 4}$ & $\mathbf{1 , 0}$ & 1422 & 99,0 & 1436 & 100 \\
Morte & $\mathbf{3 4}$ & $\mathbf{2 , 4}$ & 1402 & 97,6 & 1436 & 100 \\
\hline
\end{tabular}

Notas: n/a - não se aplica (Situação não registada)

Detalharemos nas tabelas seguintes os dados anteriormente apresentados desagregados por cada categoria.

De entre as necessidades de apoio material e/ou instrumental são consideradas cinco necessidades de apoio. $\mathrm{O}$ apoio mais frequentemente sinalizado é o relativo a apoio para prestação pecuniária $(n=595)$, seguindo-se as necessidades de produtos de apoio $(n=73)$. Na generalidade, os apoios são sinalizados ou solicitados uma ou duas vezes por cada sujeito, à exceção do apoio para prestação pecuniária, tendo sido solicitado até 5 vezes pelo mesmo sujeito (Tabela 7). 


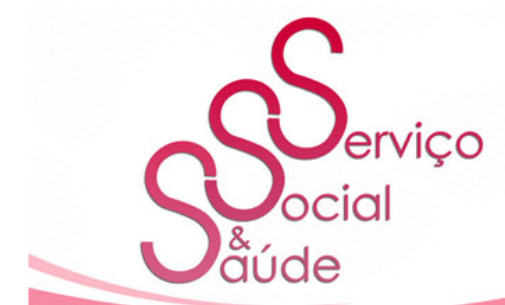

ISSN 2446-5992

(c) (1) (-)

doi: $10.20396 /$ sss.v0i0.00000000

Tabela 7.

Necessidades de Apoio Material e/ou Instrumental

\begin{tabular}{lccccccc}
\hline$N=1436(100 \%)$ & $n$ & $\boldsymbol{M}$ & $\boldsymbol{D P}$ & Mín & Máx & Mo & $\begin{array}{c}\text { Mo }= \\
\boldsymbol{1}\end{array}$ \\
\hline Apoio alimentar & 39 & 1,026 & 0,160 & 1,00 & 2,00 & 1,00 & 97,4 \\
Apoio em vestiário & 10 & 1,10 & 0,316 & 1,00 & 2,00 & 1,00 & 90,0 \\
Apoio para prestação pecuniária & 595 & 1,171 & 0,500 & 1,00 & 5,00 & 1,00 & 86,4 \\
Apoio habitacional & 40 & 1,075 & 0,267 & 1,00 & 2,00 & 1,00 & 92,5 \\
Produtos de apoio & 73 & 1,027 & 0,164 & 1,00 & 2,00 & 1,00 & 97,3 \\
TOTAL - Necessidades de Apoio Material & 689 & 1,257 & 0,644 & 1,00 & 6,00 & 1,00 & 81,9 \\
e/ou Instrumental & & & & & & & \\
\hline
\end{tabular}

De entre as necessidades de apoio logístico consideramos duas necessidades, sendo o apoio mais frequentemente sinalizado o relativo a férias $(n=253)$, seguido do relativo a transportes $(n=147)$. Cada um destes tipos de necessidades pode ter sinalizações ou solicitações múltiplas no processo interventivo, sendo que as necessidades de agilizar recursos para férias variam entre 1 e 15 vezes para cada indivíduo, apresentando uma frequência média de 1,514 vezes. Já as necessidades de apoio em transporte podem variar entre 1 a 9 por sujeito, com uma frequência média de 1,191 solicitações (Tabela 8).

Tabela 8.

Necessidades de Apoio Logístico

\begin{tabular}{|c|c|c|c|c|c|c|c|}
\hline$N=1436(100 \%)$ & $n$ & $M$ & $D P$ & Mín & Máx & Mo & $\begin{array}{c}\% M o= \\
1\end{array}$ \\
\hline Férias & 253 & 1,514 & 1,177 & 1,00 & 15,00 & 1,00 & 69,2 \\
\hline Transportes & 147 & 1,191 & 0,822 & 1,00 & 9,00 & 1,00 & 89,8 \\
\hline TOTAL - Necessidades de Apoio Logístico & 390 & 1,431 & 1,096 & 1,00 & 15,00 & 1,00 & 74,4 \\
\hline
\end{tabular}

De entre as necessidades de integração de resposta ocupacional consideram-se cinco necessidades. $\mathrm{O}$ apoio à formação e ao emprego são os apoios mais frequentemente sinalizados ( $n=90$ e $n=40$, respetivamente), representando as necessidades de integração de voluntariado, atividade física e de atividade lúdica frequências mais baixas. $\mathrm{O}$ apoio para integração de voluntariado, para formação ou para apoio ao emprego são sinalizados ou solicitados uma ou duas vezes por cada

\begin{tabular}{l|l|l|l|l|l|l|}
\hline Serv. Soc. \& Saúde & Campinas, SP & v. 17 & n. 1 [25] & p.31-64 & jan./jun. 2018 & e-ISSN 2446-5992 \\
\hline
\end{tabular}




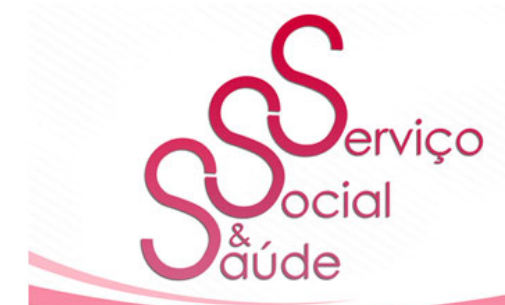

ISSN 2446-5992

(c) (1) (2)

doi: $10.20396 /$ sss.v0i0.00000000

44

sujeito, já os apoios para atividade física e lúdica só foram solicitados uma vez por cada um, assim, os valores médios estão pertos dos valores modais para a frequência de necessidade de apoio (1) (Tabela 9).

Tabela 9.

Necessidade de Integração de Resposta Ocupacional

\begin{tabular}{lccccccc}
\hline$N=1436(100 \%)$ & $\boldsymbol{n}$ & $\boldsymbol{M}$ & $\boldsymbol{D P}$ & Mín & Máx & Mo & $\begin{array}{c}\text { Mo }= \\
\boldsymbol{1}\end{array}$ \\
\hline Voluntariado & 15 & 1,067 & 0,258 & 1,00 & 2,00 & 1,00 & 93.3 \\
Atividade física & 15 & 1,000 & 0,000 & 1,00 & 1,00 & 1,00 & 100 \\
Atividade lúdica & 6 & 1,000 & 0,000 & 1,00 & 1,00 & 1,00 & 100 \\
Apoio à formação & 90 & 1,022 & 0,148 & 1,00 & 2,00 & 1,00 & 97.8 \\
Apoio ao emprego & 44 & 1,068 & 0,255 & 1,00 & 2,00 & 1,00 & 93.2 \\
TOTAL - Necessidade de Integração de & 151 & 1,166 & 0,454 & 1,00 & 4,00 & 1,00 & 86.1 \\
Resposta Ocupacional & & & & & & & \\
\hline
\end{tabular}

De entre as necessidades de integração de resposta social tivemos em conta quatro necessidades. A necessidade de integração em apoio domiciliário é a mais frequentemente sinalizada $(n=125)$, seguida de integração em ERPI ou em família de acolhimento $(n=71)$ e de integração em centro de dia $(n=68)$, registando-se menor número de casos com necessidade de resposta ao nível dos cuidados continuados integrados $(n=34)$. As necessidades de integração em centro de dia e em estrutura residencial para idosos ou família de acolhimento são sinalizadas 1 a duas vezes em cada caso, já a necessidade de apoio para integração nas duas outras respostas sociais é sinalizada uma a três vezes por cada sujeito (Tabela 10). 


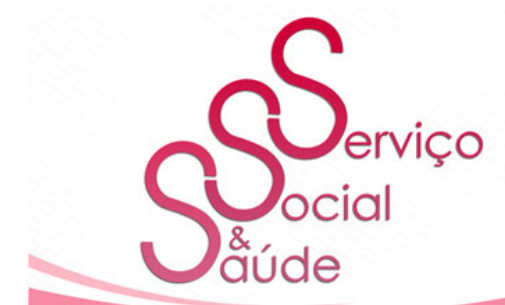

ISSN 2446-5992

(c) (1) (3)

doi: 10.20396/sss.v0i0.00000000

Tabela 10.

Necessidade de Integração de Resposta Social

\begin{tabular}{|c|c|c|c|c|c|c|c|}
\hline$N=1436(100 \%)$ & $n$ & $M$ & $D P$ & Mín & Máx & Mo & $\begin{array}{c}\% M o= \\
1\end{array}$ \\
\hline Apoio domiciliário & 125 & 1,056 & 0,231 & 1,00 & 2,00 & 1,00 & 93.7 \\
\hline Centro de dia & 68 & 1,059 & 0,293 & 1,00 & 3,00 & 1,00 & 95.6 \\
\hline $\begin{array}{l}\text { Estrutura Residencial para Idosos ou } \\
\text { Família de acolhimento }\end{array}$ & 71 & 1,014 & 0,119 & 1,00 & 2,00 & 1,00 & 93 \\
\hline Cuidados Continuados Integrados & 34 & 1,118 & 0,409 & 1,00 & 3,00 & 1,00 & 91.4 \\
\hline $\begin{array}{l}\text { TOTAL - Necessidade de Integração de } \\
\text { Resposta Social }\end{array}$ & 255 & 1,231 & 0,579 & 1,00 & 6,00 & 1,00 & 80.8 \\
\hline
\end{tabular}

De entre as necessidades de advocacy e de intervenção psicossocial consideraram-se cinco necessidades. A necessidade de intervenção familiar destacou-se como a mais frequentemente sinalizada $(n=418)$, registando-se entre 1 a 10 vezes por sujeito, como uma frequência média de 1,349. Registaram-se necessidades de regularização de documentação e de apoio jurídico em 35 e 19 casos, respetivamente. As necessidades com menor frequência são de apoio à vítima e de encaminhamento para Centros de Respostas Integradas. Os valores médios para as frequências de necessidade de apoio nesta categoria estão pertos dos valores modais (1) (Tabela 11).

Tabela 11.

Necessidade de Advocacy e de Intervenção Psicossocial

\begin{tabular}{|c|c|c|c|c|c|c|c|}
\hline$N=1436(100 \%)$ & $n$ & $M$ & $D P$ & Mín & Máx & Mo & $\begin{array}{c}\% M o= \\
1\end{array}$ \\
\hline Regularização de Documentação & 35 & 1,029 & 0,169 & 1,00 & 2,00 & 1,00 & 97,1 \\
\hline Apoio Jurídico & 19 & 1,158 & 0,375 & 1,00 & 2,00 & 1,00 & 84,2 \\
\hline Apoio à Vitima & 2 & 1,000 & 0,000 & 1,00 & 1,00 & 1,00 & 100 \\
\hline Encaminhamento para CRI (PLA e CAD) & 3 & 1,000 & 0,000 & 1,00 & 1,00 & 1,00 & 100 \\
\hline Intervenção com a família & 418 & 1,349 & 0,827 & 1,00 & 10,00 & 1,00 & 77,8 \\
\hline $\begin{array}{l}\text { TOTAL - Necessidade de Advocacy e de } \\
\text { Intervenção Psicossocial }\end{array}$ & 462 & 1,357 & 0,823 & 1,00 & 10,00 & 1,00 & 76,8 \\
\hline
\end{tabular}




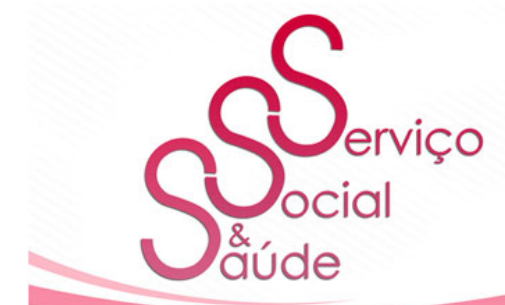

ISSN 2446-5992

(c) (1)(2)

doi: $10.20396 /$ sss.v0i0.00000000

À exceção da necessidade de integração de resposta social, verificou-se uma associação estatisticamente significativa entre a distribuição os tipos de necessidades sinalizadas e da variável resposta adequada $(p<0,001)$. Quando houve necessidade sinalizada, as respostas adequadas registaram frequências superiores às outras respostas ( $n=393$ vs. 296; $n=334$ vs. 56; $n=172$ vs. 83; $n=379$ vs. 83), à exceção da necessidade de integração de resposta ocupacional em que a distribuição foi semelhante ( $n=75 v s$. 76).

Como referimos na Tabela 6 , houve 910 casos de respostas adequadas para as situações de 63,4\% dos sujeitos com necessidades sinalizadas. Quando cruzamos as necessidades sinalizadas por categoria com as respostas avaliadas como adequadas, percebemos que há uma associação estatisticamente significativa nos casos das necessidades de Apoio Material e/ou Instrumental, Apoio Logístico, Integração de Resposta Ocupacional e Advocacy e Intervenção Psicossocial $(p<0,001)$. É de realçar que sempre que houve necessidades identificadas, registou-se um número mais elevado de respostas adequadas do que outro tipo de respostas (393 vs. 296; 334 vs. 56; 172 vs. 83; 379 vs. 83), excetuando no caso da integração de resposta ocupacional, em que este número é similar (75 vs. 76) (Tabela 12). 


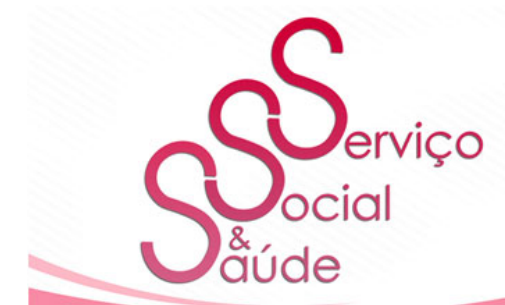

ISSN 2446-5992

(1) (1)(-)

doi: 10.20396/sss.v0i0.00000000

47

Tabela 12.

Contingência entre a resposta adequada e o tipo de necessidade sinalizada

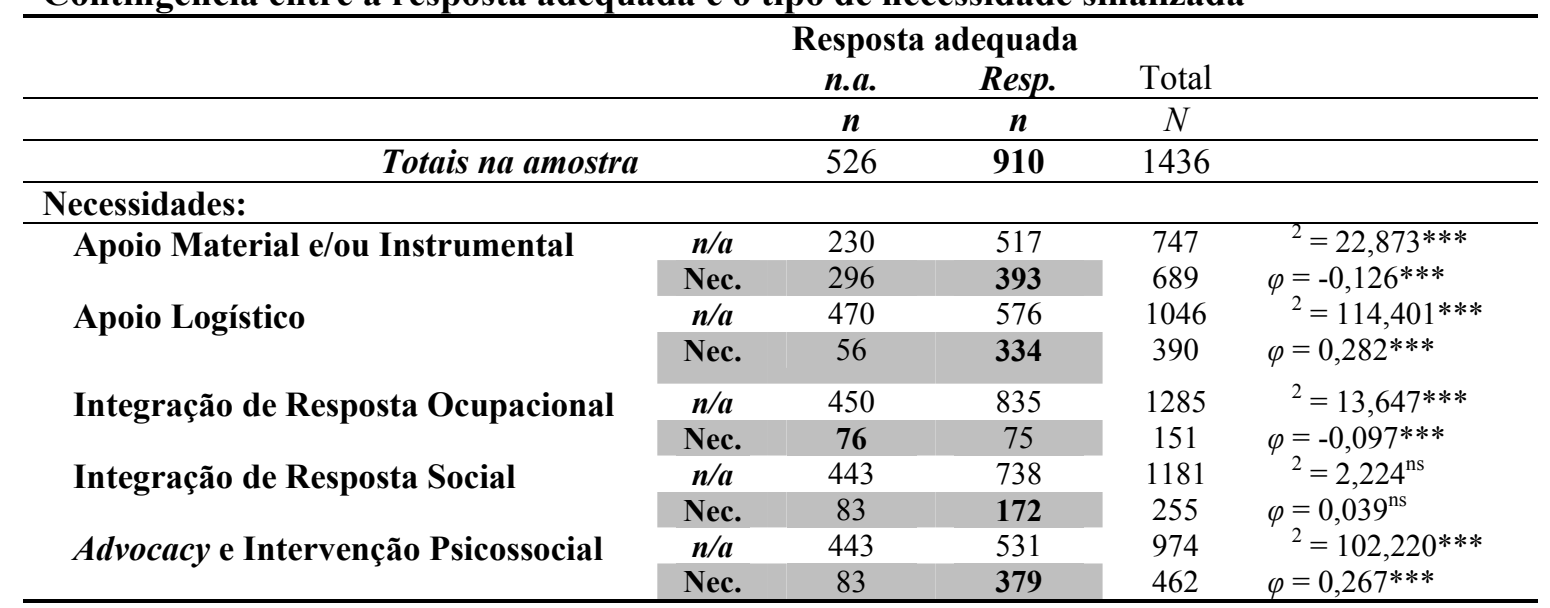

Notas: n.a. - não se aplica (Situação não registada); Resp. - Resposta (Situação em que houve resposta); Nec. - Necessidade (Situação em que houve necessidade sinalizada)

$N$ - amostra total; $n$ - frequência; ${ }^{2}$ - Qui-quadrado; $\varphi$ - Phi.

Significância estatística (valor de $p$ ): $*^{*} \leq \leq 0,05 ; * * p \leq 0,01 ; * * * p \leq 0,001$, n.s. - não significativo

Avaliámos as diferenças nas médias entre grupos para o número médio de necessidades sinalizadas segundo características sociodemográficas (sexo, grupo etário, estado civil, tipo de família e zona de origem). Foram encontradas diferenças significativas para o estado civil $(p<0,01)$, sendo que os viúvos registam médias superiores aos outros estados, assim como para o tipo de família $(p<0,01)$, sendo os indivíduos institucionalizados e em famílias de acolhimento a apresentarem médias mais elevadas de necessidades relativamente aos sujeitos integrados em outras tipologias familiares.

Apesar de não terem emergido diferenças estatisticamente significativas entre as categorias das variáveis sexo, grupo etário e zona de origem $(p>0,05)$, registaram-se tendências que sublinhamos, havendo subgrupos na amostra que revelam um nível mais elevado de sinalização de necessidades relativamente aos restantes, a saber: as mulheres, os adultos; os idosos-idosos; os sujeitos oriundos dos PALOP (Tabela 13). 


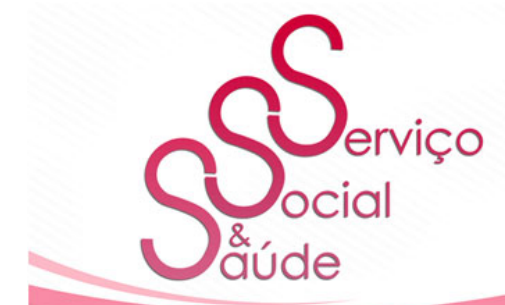

ISSN 2446-5992

(c) (i) (2)

doi: $10.20396 /$ sss.v0i0.00000000

48

Tabela 13.

Número médio de necessidades sinalizadas segundo características sociodemográficas

\begin{tabular}{|c|c|c|c|c|}
\hline & $n$ & $M$ & $D P$ & Testes \\
\hline \multicolumn{5}{|l|}{ Sexo } \\
\hline Feminino & 565 & 1,804 & 1,311 & \multirow{2}{*}{$\begin{array}{l}U= \\
237262,5^{\mathrm{ns}}\end{array}$} \\
\hline Masculino & 871 & 1,747 & 1,294 & \\
\hline \multicolumn{5}{|l|}{ Grupo etário } \\
\hline jovem adultícia (19-35) & 63 & 1,746 & 0,933 & \multirow{5}{*}{$\begin{array}{l}H=6,489 \\
\mathrm{~ns}\end{array}$} \\
\hline adultícia $(36-64)$ & 526 & 1,819 & 1,328 & \\
\hline idoso-jovem (65-74) & 341 & 1,701 & 1,200 & \\
\hline idoso $(75-84)$ & 355 & 1,738 & 1,356 & \\
\hline idoso-idoso $(>=85)$ & 151 & 1,834 & 1,421 & \\
\hline \multicolumn{5}{|l|}{ Estado Civil } \\
\hline Solteiro(a) & 224 & 1,737 & 1,074 & \multirow{4}{*}{$\begin{array}{l}H= \\
11,559 * *\end{array}$} \\
\hline Casado(a) / Unido(a) de Facto & 824 & 1,715 & 1,305 & \\
\hline Divorciado(a) / Separado(a) & 131 & 1,886 & 1,134 & \\
\hline Viúvo(a) & 256 & 1,918 & 1,520 & \\
\hline \multicolumn{5}{|l|}{ Tipo de família } \\
\hline Família Nuclear com Filhos & 678 & 1,673 & 1,222 & \multirow{9}{*}{$\begin{array}{l}H= \\
20,193 * *\end{array}$} \\
\hline Família Nuclear sem Filhos & 64 & 1,672 & 1,481 & \\
\hline Família Alargada & 189 & 1,905 & 1,285 & \\
\hline Família Monoparental & 148 & 1,804 & 1,035 & \\
\hline Família Reconstituída & 40 & 1,975 & 1,561 & \\
\hline Família Unipessoal & 181 & 1,840 & 1,528 & \\
\hline $\begin{array}{l}\text { Agregados com membros coabitantes não } \\
\text { aparentado }\end{array}$ & 56 & 1,750 & 1,210 & \\
\hline Família de Acolhimento & 6 & 2,000 & 0,894 & \\
\hline Integrado em Instituição & 74 & 2,041 & 1,617 & \\
\hline \multicolumn{5}{|l|}{ Zona de Origem } \\
\hline Portugal & 1224 & 1,745 & 1,280 & \multirow{4}{*}{$H=4,920^{\mathrm{ns}}$} \\
\hline PALOP & 178 & 1,961 & 1,490 & \\
\hline Países Europeus & 9 & 1,667 & 1,118 & \\
\hline Outras Origens & 25 & 1,640 & 0,700 & \\
\hline
\end{tabular}

Notas:

$n$ - frequência: $M=$ Média; $D P=$ Desvio Padrão; $H=$ Teste de Kruskal Wallis; $U=$ Teste de MannWhitney U

PALOP - Países Africanos de Língua Oficial Portuguesa.

Significância estatística (valor de $p$ ): ${ }^{*} p \leq 0,05 ;{ }^{*} p \leq 0,01 ; * * * \leq 0,001$, n.s. - não significativo 


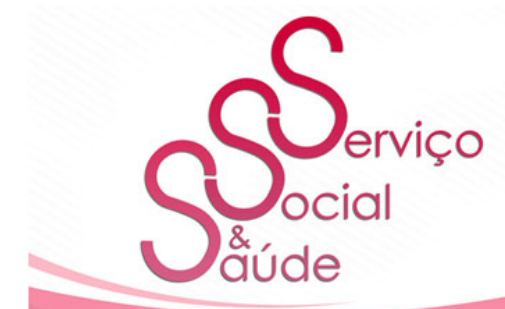

\section{ISSN 2446-5992}

(c) (1)(2)

doi: 10.20396/sss.v0i0.00000000

\section{DISCUSSÃO DOS RESULTADOS}

A doença vulnerabiliza socialmente os doentes renais crónicos, mas algumas das características da população estudada acrescenta fatores preocupantes de vulnerabilidade social às suas situações. Apesar de apresentarem idades entre os 19 e os 97 anos de idade, 59\% da amostra tem idade igual ou superior a 65 anos, sendo sobretudo indivíduos com idades avançadas, apresentando esta população em Portugal um quadro de vulnerabilidade social multidimensional e necessidades específicas de suporte social (GUADALUPE; CARDOSO, 2018). Esta é também uma amostra que apresenta habilitações literárias baixas, o que pode associar-se a eventuais dificuldades em ativar e aceder a recursos. Apesar de a maior dos participantes ser originário de Portugal $(85,2 \%)$, há uma percentagem relevante de doentes com outras origens, destacando-se os sendo os oriundos dos PALOP (12,4\%), grupo de países com os quais Portugal tem acordos de colaboração, sendo uma realidade já abordada em estudos anteriores (OLIM, GUADALUPE, MOTA, FRAGOSO, RIBEIRO, 2018), pois esta população encontra-se deslocada, pelo que apresenta vulnerabilidade acrescida.

Outro fator potenciador de vulnerabilidade associa-se ao seu enquadramento familiar. Note-se que a maioria dos doentes são casados, mas 42,5\% da amostra são solteiros, divorciados ou viúvos, o que traduz, em geral, condições quotidianas distintas na coabitação e no suporte. Atente-se que 12,9\% vivem sós, 10,3\% constituem famílias monoparentais, havendo $3,9 \%$ em agregados com coabitantes não aparentados e 5,2\% integrados em instituições. Como salientam diversos estudos, o ajustamento à DRC às suas exigências, assim como a sobrevida, são favorecidos pelo suporte social, com especial destaque para o suporte familiar (MCCLELLAN; STANWYCK; ANSON, 1993; PATEL; PETERSON; KIMMEL, 2005; TAYLOR; COMBES, 2014), sendo esta variável relevante para compreender os dados. 


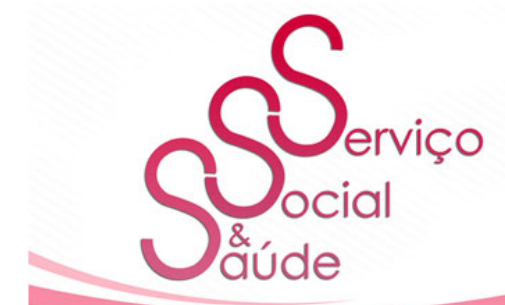

\section{ISSN 2446-5992}

(c) (1)(2)

doi: $10.20396 /$ sss.v0i0.00000000

Os doentes renais crónicos têm, em Portugal, garantido o acesso gratuito aos cuidados de saúde, quer através de unidades de saúde públicas como privadas (convencionadas), havendo atualmente cobertura nacional de unidades especializadas no tratamento da DRC. Mas estes doentes têm de adaptar-se a implicações da doença que são disruptivas e permanentes, quer ao nível da sua condição física, ao nível identitário, emocional, familiar, relacional, quer na sua relação com o trabalho e no seu estilo de vida (TONG et al., 2009). Por isso, o favorecimento de uma maior justiça social não passa apenas por permitir o acesso aos cuidados de saúde, mas de garantir também proteção, suporte e bem-estar social aos doentes, de forma compensatória, evitando que a doença desencadeie disrupção, empobrecimento e exclusão social. As necessidades manifestadas pelos doentes crónicos são uma das faces visíveis destes processos, a nível microssocial, com que o Serviço Social lida.

Os resultados evidenciam que foram sinalizadas 2550 necessidades interventivas pelo Serviço Social, no seu conjunto. Por doente, foi sinalizada uma necessidade em $58,6 \%$ dos casos, mas a média $(M=1,78)$ aproxima-se das 2 necessidades, registadas em $23,5 \%$ dos casos.

Do total de sujeitos $(N=1436)$, respetivamente, $48 \%$ apresentam necessidades de apoio material/instrumental, 31,2\% evidenciaram necessidades de advocacy e intervenção psicossocial (32,2\%), 27,2\% de apoio logístico, 17,8\% de integração em resposta social e 10,5\% em resposta ocupacional. Note-se que alguns doentes apresentam necessidades em várias categorias e alguns registam várias solicitações da mesma necessidade. As categorias que registam valores mais elevados na frequência de sinalizações são as necessidades de apoio logístico $(M=1,431)$ e as necessidades de advocacy e de intervenção psicossocial $(M=1,257)$. 


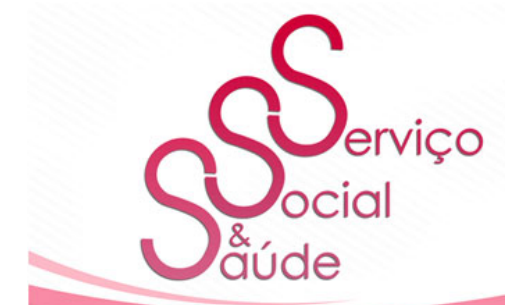

\section{ISSN 2446-5992}

(c) (1)(8)

doi: $10.20396 /$ sss.v0i0.00000000

Analisadas as diferenças no número de necessidades sinalizadas segundo as características sociodemográficas, as pessoas viúvas revelam-se como um grupo de especial atenção, tendo registado um número superior aos outros estados civis $(p<$ 0,01), assim como os doentes integrados em famílias de acolhimento ou em instituições relativamente às outras tipologias familiares $(p<0,01)$. Tal pode estar associado à falta de enquadramento num agregado familiar e à falta de suporte social quotidiano da família, sendo o sistema familiar fulcral para o sistema de provisão social em Portugal e noutros contextos culturais do sul da Europa (GUADALUPE; CARDOSO, 2018).

Emergiram da análise preliminar dos dados cinco categorias operacionais para agregar as necessidades sinalizadas: apoio material e/ou instrumental; apoio logístico; integração de resposta ocupacional; integração de resposta social; advocacy e intervenção psicossocial. Num estudo de âmbito geral, em que foram abordadas dimensões temáticas que refletem diversas esferas da vida (como o trabalho e emprego, o nível de vida, a gestão de rendimentos, o habitat, o ambiente local, as mobilidades, a educação, as competências, as redes de apoio, o bem-estar subjetivo e a saúde física e mental), resultou uma categorização mais abrangente do que a que propomos, mas que se entrecruza: necessidades físicas e de recursos; necessidades de competências e capacidades; necessidades socio afetivas; necessidades de desenvolvimento pessoal e bem estar (PINTO et al., 2010). A identificação das necessidades não satisfeitas que constituem fatores perturbadores e prejudiciais à otimização das oportunidades da vida individual e coletiva na população geral era a sua finalidade (PINTO et al., 2010), sendo que as idiossincrasias da doença crónica se associam a fatores muito específicos e contextualizados que merecem destaque em categorias que ressaltem essas especificidades.

De entre as necessidades de apoio material/instrumental, o apoio na obtenção de prestação pecuniária destaca-se, nomeadamente o apoio procedimental no acesso a 


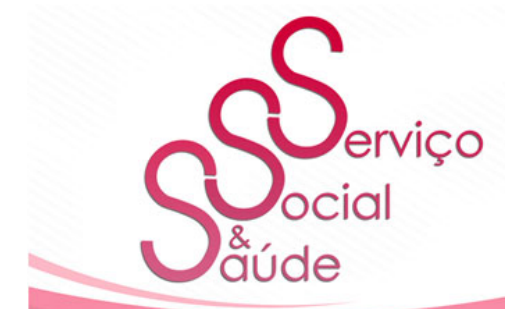

\section{ISSN 2446-5992}

(c) (1)(8)

doi: $10.20396 /$ sss.v0i0.00000000

declaração de incapacidade multiusos, benefícios fiscais, incapacidade temporária para o trabalho, complemento por dependência entre outras medidas de proteção social aplicáveis. Apesar de também constituir-se como advocacy, na sua vertente de apoio informativo e de acesso a direitos, a finalidade pecuniária enquadra-a neste tipo de necessidade de apoio. Nesta categoria também se destaca a necessidade de produtos de apoio, de apoio habitacional e de apoio alimentar, ainda que de forma menos expressiva.

Sabendo-se que as despesas diretas em saúde são o principal precipitante de pobreza em doentes crónicos, em desempregados e em idosos (WHO, 2009), as que decorrem da doença avolumam a fragilidade da situação socioeconómica das pessoas, havendo que agir no sentido de prevenir o agravamento das vulnerabilidades. O Serviço Social, ao prestar apoio de forma sistemática a estas necessidades, intervém favorecendo o ajustamento à situação de forma a amortecer ou a reparar o impacte negativo da doença a nível material ou instrumental (GUADALUPE, 2012).

Nas necessidades de apoio logístico considerou-se o apoio em férias e em transportes. O apoio na garantia de transporte assegura o acesso ao tratamento de hemodialise. $\mathrm{O}$ apoio na organização das férias pretende favorecer a vivência de um período de descanso e lazer com a garantia de cuidados de saúde noutra unidade de saúde dentro ou fora do país, na zona de destino, favorecendo assim uma maior qualidade de vida, devolvendo ao doente e à família alguma "normalidade" num contexto de grande imprevisibilidade, tal como alegam TONG et al. (2009) e OLIM (2013). O apoio a esta necessidade constitui uma intervenção complexa, exigindo planeamento e articulação estreita entre várias organizações, nomeadamente a compatibilização de tratamentos e horários em clínicas dentro ou fora do país, e o ajustamento dos mesmos à rotina de férias dos doentes e suas famílias. As consequências no estilo de vida e o isolamento social são evidenciadas pelos doentes, sentindo-se por vezes culpados por impossibilitarem maior liberdade à família (TONG 


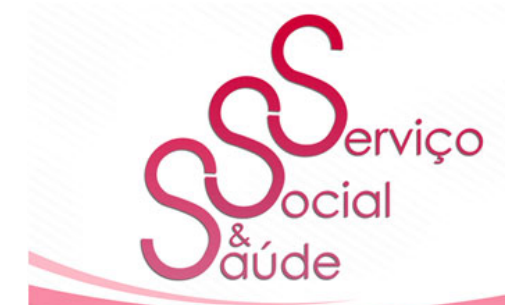

\section{ISSN 2446-5992}

(c) (1)(8)

doi: $10.20396 /$ sss.v0i0.00000000

et al., 2009), sendo as férias uma forma de quebrar esses processos. Na amostra estudada, as 253 sinalizações de necessidade de apoio para férias representam 17,6\% dos participantes, sendo que pode ainda ser uma percentagem mais residual da amostra, tendo em conta que se registaram 1,5 solicitações em média. Outro estudo manifestou preocupação com a qualidade de vida dos doentes por apenas 13\% terem tido férias desde o início da diálise (ROCCO; MERCIERI; YAVUZER, 2006). Tal mostra que é uma necessidade sentida por uma minoria, havendo que trabalhar no sentido de dar oportunidade a mais doentes de terem direito a férias, já que as pessoas com DRC reclamam mais atenção para a necessidade de haver maior investimento no favorecimento da sua capacidade de autonomia para viverem as suas vidas (JANSEN, 2012).

Ao nível das necessidades de integração em resposta ocupacional assumem maior relevo as necessidades de apoio para formação e emprego. As perdas em oportunidades de trabalho, o abandono do mercado de trabalho e as dificuldades de reinserção laboral desta população (MUEHRER et al., 2011) levam a que, nas trajetórias dos doentes hemodialisados, haja necessidade de manter uma ocupação. Ora, tal como afirmam OLIM et al. (2017) a formação é uma resposta a que os doentes tendem a aderir mais frequentemente como um meio de facilitar a transição para o trabalho, sendo a ocupação laboral mais condicionada pela imprevisibilidade da doença e pela exigência e frequência dos tratamentos.

Em relação às necessidades de integração em resposta social destacam-se as necessidades de apoio domiciliário e de estrutura residencial para idosos, assim como de família de acolhimento, sinalizações que estão diretamente relacionadas com os episódios de hospitalização recorrente que esta população enfrenta, associados à diminuição de autonomia e à incapacidade da família em assumir o seu cuidado por si só. 


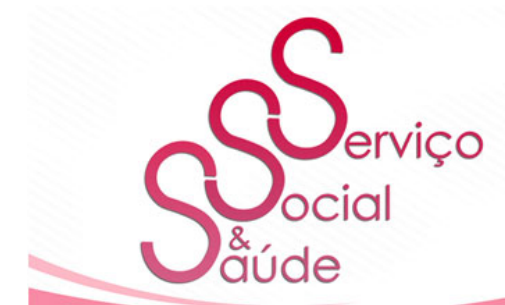

\section{ISSN 2446-5992}

(c) (1)(8)

doi: $10.20396 /$ sss.v0i0.00000000

De entre as necessidades de advocacy e de intervenção psicossocial, as necessidades de intervenção com a família são sinalizadas em maior número, isto porque a família tem igualmente necessidades que rivalizam com as necessidades do doente, tendo em conta o impacte que a doença crónica tem no sistema familiar (GUADALUPE, 2012; ROLLAND, 2000). Como antes referimos, a família assume um papel central nos cuidados informais a estes doentes, tendo de ser igualmente suportada para continuar a ter possibilidade de apoiar e cuidar com qualidade (GUADALUPE, 2012). Este suporte é de natureza psicossocial (JOHNSON; CÔRTE-REAL, 2000), no sentido de integrarem da melhor forma a doença e o tratamento, apoiando-os nas suas próprias necessidades, mobilizando os recursos necessários.

As necessidades de apoio na regularização de documentação e de apoio jurídico estão relacionadas sobretudo com os processos de "legalização" de cidadãos estrangeiros, nomeadamente dos cidadãos oriundos dos PALOP, sendo este processo essencial para garantir o acesso aos cuidados de saúde e a outros direitos em igualdade de circunstâncias com os cidadãos nacionais.

A provisão de necessidades sociais no processo interventivo constitui um desafio permanente para o Serviço Social, pois para além daquelas que são diagnosticadas no acolhimento dos doentes, há necessidades emergentes num processo dinâmico e de acompanhamento de longo prazo, como é o caso dos doentes crónicos. Os doentes com DRC em tratamento de hemodiálise beneficiam fortemente do suporte psicossocial por parte de assistentes sociais, refletindo-se em melhores resultados na sua saúde (MCCOOL et al., 2011).

Quanto à resposta às necessidades sinalizadas, em $63,4 \%$ dos casos esta foi adequada, mantendo-se o processo em aberto em 31,8\%, estando as situações em tramitação e a aguardar resposta. No caso das necessidades que não foram satisfeitas, 


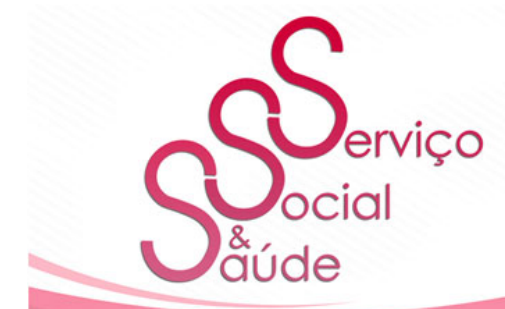

\section{ISSN 2446-5992}

(c) (1)(8)

doi: $10.20396 /$ sss.v0i0.00000000

$6,2 \%$ foi por resposta desadequada, $5,5 \%$ por inexistência de resposta, $14,1 \%$ por não adesão do doente e $6,1 \%$ por não adesão da família ao plano de intervenção delineado.

$\mathrm{Na}$ maioria das situações, os dados revelam, assim, que houve uma compatibilização entre o pedido, a necessidade e as oportunidades do sistema ou recursos sociais existentes na comunidade, registando-se associações estatisticamente significativas entre a resposta adequada e a maioria das categorias de necessidades. Entende-se que a resposta é desadequada quando se verifica posteriormente que a resposta não satisfaz as necessidades ou se apresenta como desadequada face às expectativas do doente e da família. Salientamos, no entanto, que as respostas não adequadas estão também relacionadas com o desfasamento entre o pedido e a resposta encontrada. Tal acontece regularmente ao nível das prestações sociais, quando, face ao pedido, o doente não reúne os critérios para a respetiva atribuição.

Igualmente importante é a percentagem de não adesão (20,2\%) associada frequentemente com a resposta de apoio domiciliário que, depois de efetivado, não corresponde às expectativas nem às necessidades efetivas dos doentes. A desistência deste tipo de apoio está relacionada com o facto de a família continuar a salvaguardar a prestação de cuidados e a representar o recurso mais compatível com a opção do doente e da própria família. Apesar da diversidade de funções assumidas por estes serviços, parece haver ainda trabalho a desenvolver no sentido de promover a adaptação de algumas respostas comunitárias à especificidade de cuidados ao doente com DRC, para evitar a posterior avaliação de desadequação das respostas, o que implica um trabalho de articulação e de construção conjunta de programas com diversas organizações. A não adesão está igualmente relacionada com o ânimo e atitude do doente com DRC, sendo que a apatia, a desmotivação e a depressão (CUKOR et al., 2007; IBRAHIM, SALAMONY, 2008) são estados que dificultam e até inviabilizam iniciativas de adesão a uma resposta ou recurso. 


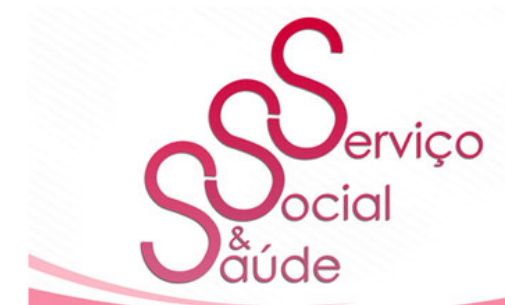

\section{ISSN 2446-5992}

(c) (1)(-)

doi: 10.20396/sss.v0i0.00000000

\section{CONCLUSÕES}

O presente estudo permite compreender a diversidade de necessidades que esta população apresenta, particularmente as decorrentes da situação de vulnerabilidade social em que muitos doentes se encontram. Os processos de doença associados a tratamentos exigentes, que condicionam a autonomia e as várias esferas da vida do doente e da família, interpelam o Serviço Social a produzir conhecimento e a refletir no sentido de equacionar respostas que satisfaçam as necessidades e promovam a sua qualidade de vida e bem-estar social.

Mais de metade dos participantes no estudo apresenta pelo menos uma necessidade, cerca de $1 / 4$ da amostra manifesta duas necessidades, tendo os restantes sido sinalizados com três ou mais necessidades. As necessidades sinalizadas foram sobretudo de apoio material/instrumental, respondidas principalmente através de medidas de política social, tendo em conta as alterações que a doença traz na relação com o trabalho e no rendimento. Destacam-se ainda as necessidades de advocacy e intervenção psicossocial, assumindo a intervenção com a família um maior relevo, compreendendose pela crise que as famílias vivenciam neste contexto e pelas necessidades sentidas pelas mesmas, diferentes das experienciadas pelos pacientes, relacionadas sobretudo com o papel de cuidador. São também relevantes as necessidades de apoio logístico que tendem a ser respondidas através de medidas compensatórias para minimizar os impactes negativos da doença no estilo de vida do doente e da família.

$\mathrm{Na}$ maioria das situações, as necessidades foram satisfeitas, evidenciando coerência no processo interventivo em que as respostas são co-construídas pelos vários atores sociais e sistemas implicados no processo: doente, família, assistente social, equipa clínica e estruturas da comunidade. As respostas posteriormente avaliadas como desadequadas à situação e a taxa de não adesão às respostas equacionadas para provisão das necessidades, obrigam a uma reflexão para equacionar alternativas viáveis para

\begin{tabular}{|l|l|l|l|l|l|l} 
Serv. Soc. \& Saúde & Campinas, SP & v. 17 & n. 1 [25] & p.31-64 & jan./jun. 2018 & e-ISSN 2446-5992
\end{tabular}




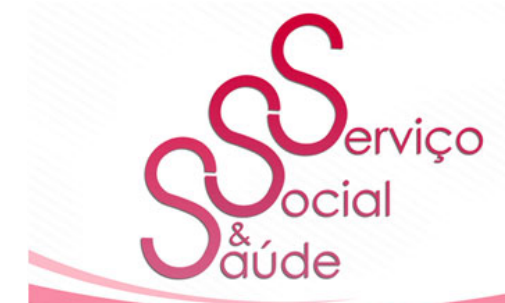

ISSN 2446-5992

(c) (1)(2)

doi: $10.20396 /$ sss.v0i0.00000000

colmatar as necessidades de forma efetiva, sendo que tais respostas não se mostram capazes de responder às exigências e condicionalismos desta doença crónica, e quase nunca estão na égide das equipas do Serviço Social dos serviços de saúde.

O reforço do suporte social e das condições de vida em geral, através da provisão de necessidades sociais, pretendem beneficiar o estado clínico dos doentes e o seu bem-estar psicossocial. A sistematização, conhecimento e análise das necessidades sociais dos doentes renais crónicos, permite favorecer o diagnóstico social desta população, equacionar o desenvolvimento de novos estudos, promover o debate profissional e potenciar o desenho de políticas organizacionais e sociais que otimizem as estratégias de intervenção social e a proteção social dos doentes e das suas famílias.

Recebido em maio de 2018 - Aprovado em junho de 2018

\section{REFERÊNCIAS}

BEDER, J. Evaluation research on the effectiveness of social work intervention on dialysis patients: the first three months. Social Work in Health Care, v. 30, n. 1, p. 1530, 1999. doi: 10.1300/J010v30n01_02

BRAGE, L. B. Marco conceptual para el analisis de las necesidades sociales. Cuadernos de Trabajo Social, v. 1, 63-75, 1988. Disponível em: https://revistas.ucm.es/index.php/CUTS/article/viewFile/CUTS8888110063A/8655

CUKOR, D.; COHEN, S.; PETERSON, R.; KIMMEL, P. Psychosocial Aspects of Chronic Disease: ESRD as a Paradigmatic Illness. J Am Soc Nephrol. v. 18. p. 30423055, 2007. doi: 10.1681/ASN.2007030345 


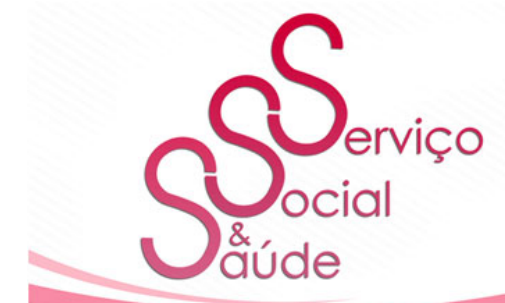

ISSN 2446-5992

(c) (i) (2)

doi: $10.20396 /$ sss.v0i0.00000000

DOYAL, L.; GOUGH, I. A Theory of Human Need. London: MacMillan, 1991.

DOVER, M. A. Human Needs: Overview. Subject: Ethics and Values, Human Behavior, International and Global Issues, Populations and Practice Settings, Social Justice and Human Rights. In Encyclopedia of Social Work. National Association of Social Workers Press; Oxford University Press, 2016. doi: 10.1093/acrefore/9780199975839.013.554

FERREIRA, P.; ANES, E. Medição da qualidade de vida de insuficientes renais crónicos: criação da versão portuguesa do KDQOL-SF. Revista Portuguesa de Saúde Pública, v. 28, n. 1, p. 31-39, 2010. Disponível em: http://www.scielo.mec.pt/scielo.php?script=sci abstract\&pid=S0870$\underline{90252010000100004 \& \operatorname{lng}=\mathrm{pt} \& \mathrm{nrm}=\mathrm{iso}}$

GUADALUPE, S.; CARDOSO, J. As redes de suporte social informal como fontes de provisão social em Portugal: O caso da população idosa. Sociedade \& Estado, v. 33, n. 1, p. 13-248, 2018. doi: 10.1590/s0102-699220183301009

GUADALUPE, S. A intervenção do serviço social na saúde com famílias e em redes de suporte social. In Carvalho, M. I. L. B. (Coord.). Serviço Social na Saúde. Lisboa: Pactor, Lidel, 2012, p. 183-217.

GUADALUPE, S. Intervenção em rede: Serviço Social, sistémica e redes de suporte social (2. edição). Coimbra: Imprensa da Universidade, 2016. doi: 10.14195/978-98926-0866-2

IBRAHIM, S.; SALAMONY, O. Depression, Quality of life and MalnutritionInflammation Scores in Hemodialysis Patients. American Journal of Nephrology, v. 28, n. 5, p. 784-91, 2008. doi: 10.1159/000131101. 


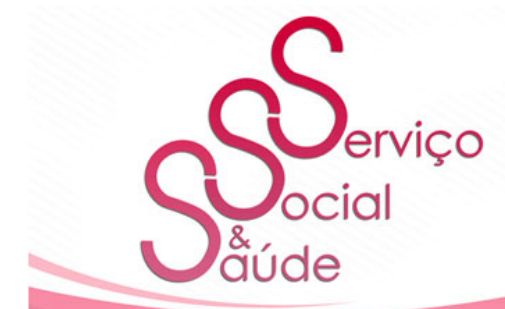

ISSN 2446-5992

(c) (i) (2)

doi: $10.20396 /$ sss.v0i0.00000000

JANSEN, D.; RIJKEN, M.; HEIJMANS, M.; KAPTEIN, A.; GROENEWEGEN, P. Psychological and social aspects of living with chronic kidney disease. In M. Sahay. Chronic kidney disease and renal transplantation. Rijeka: InTech, 2012, p. 47-74. doi: 10.5772/25992 Disponível em: http://cdn.intechopen.com/pdfs/28037/InTechPsychological and social aspects of living with chronic kidney disease.pdf JOHNS, T.; YEE, J.; SMITH-JULES, T.; CAMPBELL, R.; BAUER, C. Interdisciplinary care clinics in chronic kidney disease. BMC Nephrology. v. 16, n. 161, 2015. doi: 10.1186/s12882-015-0158-6

JOHNSON, B.; CÔRTE-REAL, F. O som do silêncio - Uma reflexão a partir do Serviço Social da Saúde em Hospital. Intervenção Social. v. 21, p. 33-44, 2000. Disponível em: http://revistas.lis.ulusiada.pt/index.php/is/article/view/1106 MANSUR, H. N.; DAMASCENO, V. O.; BASTOS, M. G. Prevalência da fragilidade entre os pacientes com doença renal crônica em tratamento conservador e em diálise. Jornal Brasileiro de Nefrologia, v. 34, n. 2, p. 153-160, 2012. doi: $10.1590 / \mathrm{S} 0101-28002012000200008$

MCCLELLAN, W.; STANWYCK, D.; ANSON, C. Social support and subsequent mortality among patients with end-stage renal disease. Journal of the American Society of Nephrology, v. 4, n. 4, p. 1028-34, 1993. Disponível em: https://www.ncbi.nlm.nih.gov/pubmed/8286710

MCCOOL, M.; JOHNSTONE, S.; SLEDGE, R.; WITTEN, B.; CONTILlO, M.; AEBEL-GROESCH, K.; HAFNER, J. The promise of symptom-targeted intervention to manage depression in dialysis patients. Nephrology News \& Issues, v. 25, n. 6, p. 3237, 2011. Disponível em: https://www.ncbi.nlm.nih.gov/pubmed/21608458 


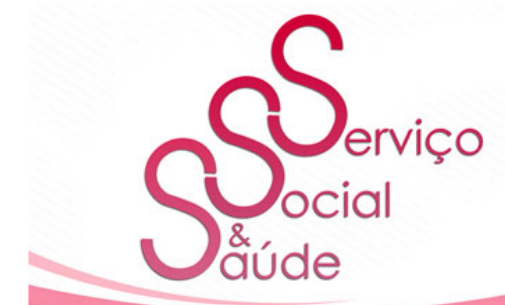

ISSN 2446-5992

(c) (i) (2)

doi: 10.20396/sss.v0i0.00000000

MUEHRER, R.; SCHATELL, D.; WITTEN, B.; GANGNON, R.; BECKER, B. E.; HOFMANN, M. Factors affecting employment at initiation of dialysis. Clinical Journal of American Society of Nephrology, v. 6, n. 3, p. 489-495, 2011. doi: 10.2215/CJN.02550310.

OLIM, M. F. O Impacto da Doença Renal Crónica e tratamento nas dinâmicas familiares do paciente. Tese (Mestrado em Serviço Social). Lisboa: Universidade Católica Portuguesa $2013 . \quad$ Docial, Disponível em: https://repositorio.ucp.pt/handle/10400.14/13836

OLIM, M. F.; CARRASCO, L.; PIMENTA, J.; SILVA, F.; TORRES, S.; DANTAS, J. Treino e reforço de competências em doentes renais crónicos em hemodiálise - $\mathrm{O}$ Programa "Acredita+ e Segue": Resultados preliminares. Revista Portuguesa de Investigação Comportamental e Social, v. 3, n. 2, p. 21-31, 2017. doi: 10.7342/ismt.rpics.2017.3.2.56

OliM, M. F.; GUADALUPE, S.; MOTA, F.; FRAGOSO, P.; RIBEIRO, S. Sociographic Profile of Hemodialysis Patients in Portugal. Journal of Nephrology Social Work. v. 42, n. 1, p. 9-20, 2018. Disponível em: https://www.kidney.org/sites/default/files/v42a a1.pdf

PATEL, S.; PETERSON, R; KIMMEL, P. The impact of social support on end-stage renal disease. Semin Dial. v. 18, n. 2, p. 98-102, 2005. doi: 10.1111/j.1525139X.2005.18203.X

PINTO, T. C.; GUERrA, I.; MARTINS, M.; ALMEIDA, S. À Tona de agua I: Necessidades em Portugal, Tradição e Tendências Emergentes. Lisboa: Tinta da China, 2010. 


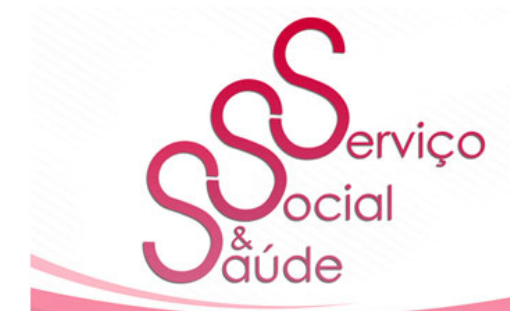

ISSN 2446-5992

(c) (i) (2)

doi: $10.20396 /$ sss.v0i0.00000000

RASCANU, R.; RADU, S. Psycho-social assessment of patients with chronic renal diseases undergoing dialysis. Procedia - Social and Behavioral Sciences. v. 127, p. 379-385, 2014. doi: 10.1016/j.sbspro.2014.03.275

ROCCO, D. G.; MERCIERI, A.; YAVUZER, G. Multidimensional health-status assessment of chronic hemodialysis patients: the impact on quality of life. Europa Medicophysica, v. 42, n. 2, p. 113-119, 2006. Disponível em: https://www.minervamedica.it/en/journals/europamedicophysica/article.php?cod=R33Y2006N02A0113

ROLLAND, J. Doença crônica e o ciclo de vida familiar. In B. Carter; M. McGoldrick. As mudanças no ciclo de vida familiar: uma estrutura para a terapia familiar (2. edição). Porto Alegre: Artes Médicas, 1995, p. 373-392

ROLLAND, J. Familias, enfermedad y discapacidad - una propuesta desde la terapia sistémica. Barcelona: Gedisa, 2000.

SALATI, M. I.; HOSSNE, W.; PESSINI, L. Vulnerabilidade referida pelos pacientes renais crônicos - considerações bioéticas. Revista Bioethikos, v. 5, n. 4, p. 434-442, 2011. Disponível em: https://www.saocamilo-sp.br/pdf/bioethikos/89/A10.pdf

SANDERS-PINHEIRO, H. Social diagnosis of chronic kidney disease patients in preparation for living donor renal transplantation. Transplantation Proceedings, v. 44, n. 8, p. 2341-2343, 2012. doi: 10.1016/j.transproceed.2012.07.012

SHEPPARD, M.; WOODCOCK, J. Need as an operating concept: the case of social work with children and families. Child \& Family Social Work, v. 4, p. 67-76, 1999. doi: 10.1046/j.1365-2206.1999.00104.x

SOUSA, L.; RELVAS, A.; MENDES, A. Enfrentar a velhice e a doença crónica. Lisboa: Climepsi, 2007. 


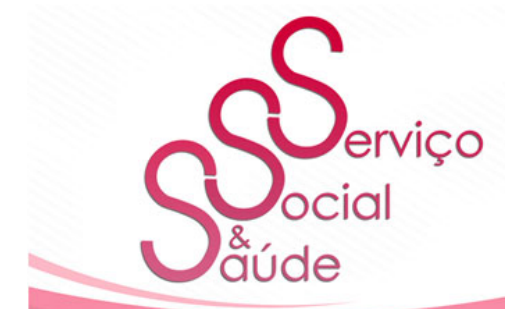

ISSN 2446-5992

(c) (i) (2)

doi: $10.20396 /$ sss.v0i0.00000000

TAYLOR, F.; COMBES, G. Supporting the emotional and psychological needs of end-stage renal disease patients. Study Report. Appendix 6: Literature Review. CLAHRC WM. University of Birmingham, 2014. Disponível em: https://warwick.ac.uk/fac/sci/med/about/centres/clahrc/research/theme4-integrated$\underline{\text { holistic-care-chronic- }}$

disease/publications/supporting_the emotional_and_psychological_needs_of_esrd_app endix.pdf

TIRAPANI, L.; PINHEIRO, H.; MANSUR, H.; OLIVEIRA, D.; NUNES, R.; HUAIRA, H.; HUAIRA, C.; GRINCENKOV, F.; BASTOS, M.; FERNANDES, N. Impacto da vulnerabilidade social nos desfechos de pacientes com doença renal crônica pré-dialítica em um centro interdisciplinar. J. Bras. Nefrologia, v. 37, n. 1, p. 19-26, 2015. doi: $10.5935 / 0101-2800.20150004$

TONG, A.; SAINSBURY, P.; CHADBAN, S.; WALKER, R. G.; HARRIS, D. C.; MCARTER, S.; HALL, B.; HAWLEY, C.; CRAIG, J. C. Patients' experiences and perspectives of living with CKD. American Journal of Kidney Diseases, v. 53, n. 4, p. A33-A35, 2009. doi: 10.1053/j.ajkd.2008.10.050

TURCHETTI, G.; BELLELLI, S.; AMATO, M.; BIANCHI, S.; CONTI, P.; CUPISTI, A.; PANICHI, V.; ROSATI, A.; PIZZARELLI F. The social cost of chronic kidney disease in Italy. Eur J Health Econ, v. 18, p. 847-858, 2017. doi: 10.1007/s10198-01608301

WALSH, F. Fortalecendo a Resiliência Familiar. São Paulo: Roca, 2005.

WHO - WORLD HEALTH ORGANIZATION - Programmes and Projects, Health action in crises, Definitions, About HAC. Genéve, 2007. Disponível em: http://www.who.int/hac/about/definitions/en/index.html 


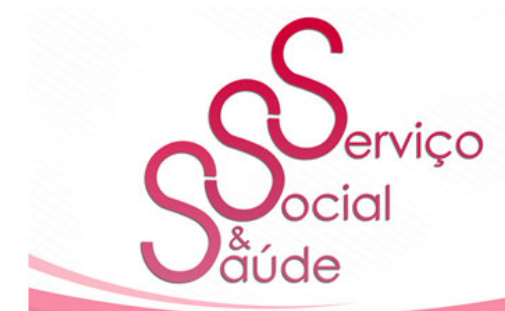

ISSN 2446-5992

(c) (1)(-)

doi: 10.20396/sss.v0i0.00000000

WHO - WORLD HEALTH ORGANIZATION. Health in times of global economic

crisis. Genéve, 2009. Disponível em: http://www.euro.who.int/en/health-topics/Healthsystems/health-systems-governance/publications/2009/health-in-times-of-globaleconomic-crisis-implications-for-the-who-european-region-2009 


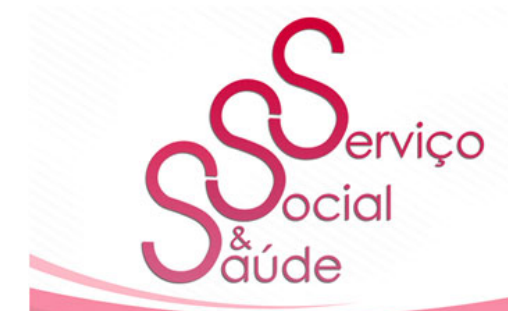

\section{ISSN 2446-5992}

(C) 100

doi: 10.20396/sss.v0i0.00000000

64 